\title{
0 reinado dos estudos de caso na teoria das organizações: imprecisões e alternativas
}

\author{
Luiz Alberto Mariz * \\ Sueli Goulart ** \\ Helder Pontes Régis ${ }^{* * k}$ \\ Debora Dourado*twk
}

\section{Resumo}

Com o amadurecimento do campo da Administração como área de conhecimento, verifica-se a busca de sua consolidação no âmbito das ciências sociais. Considerando a centralidade da questão metodológica para a qualidade do conhecimento na área de Teoria das Organizações, este trabalho apresenta revisão crítica da metodologia utilizada nos trabalhos publicados nos anais do ENANPAD, de 1999 a 2002. 0 objetivo é contribuir com as discussões sobre práticas metodológicas, especialmente no que diz respeito ao uso do estudo de caso como estratégia de pesquisa. As informações coletadas foram subdivididas em três grupos contemplando o delineamento da pesquisa, as técnicas de coleta de dados e as dimensões e recursos de análise de dados. Os resultados deste estudo apontaram para predominância de estudos qualitativos, uma relativa banalização no uso da estratégia de estudo de caso, tendência à adoção de pressupostos objetivistas, utilização de métodos interpretativistas de análise, entre outros. Esta análise sugere que a categoria de estudo qualitativo básico pode ser utilizada com proveito pelos pesquisadores brasileiros na área de Administração.

Palavras-chave: Estudo de Caso; Metodologia de pesquisa em Administração.

\begin{abstract}
With the process of maturing in Administration field as knowledge area, is verified the search of its consolidation in the scope of the social sciences. Considering the centrality of the methodological subject for the quality of the knowledge produced in the area of Organizational Theory, this work presents a critical revision of the methodology used in the article published in the annals of ENANPAD, in the period from 1999 to 2002. The main objective is to contribute with the discussions on methodological practices, especially in what it concerns the use of the case study as research strategy. The informations collected were subdivided in three groups contemplating the research design, the techniques of data collection and the dimensions and resources of data analysis. The main results of this study show the predominance of qualitative studies, a relative banality in the use of the case study strategy, the tendency to the objective dimensions, use of interpretative analysis methods, among others. This analysis suggests that the category of basic qualitative study can be used with advantage by the Brazilian researchers in the Administration area.
\end{abstract}

Key words: Case Study ; Research Metodology in Administration

\section{Introdução}

A preocupação com a produção do conhecimento em administração tem recebido significativa atenção dos pesquisadores brasileiros, o que é revelado pela quantidade de textos publicados em periódicos ou anais de eventos e pela criação, em 2001, da área de Ensino e Pesquisa em Administração no âmbito do Encontro Anual da Associação Nacional dos Programas de Pós-Graduação em Administração (Enanpad). Essa área é voltada

\footnotetext{
* Doutorando no Programa de Pós-Graduação em Administração da Universidade Federal de Pernambuco. Professor do Curso de Administração da Faculdade Boa Viagem. E-mail: l.a.mariz@uol.com.br

** Doutoranda no Programa de Pós-Graduação em Administração da Universidade Federal de Pernambuco. Bibliotecária na Universidade Federal de Alagoas. E-mail: : sueligoulart@ uol.com.br

*** Doutorando no Programa de Pós-Graduação em Administração da Universidade Federal de Pernambuco. Professor da UNICAP-Universidade Católica de Pernambuco. E-mail: hregis@ hotlink.com.br

**** Doutoranda pelo Programa de Pós-Graduação em Administração da UFPE (Propad/UFPE). Professora do Departamento de Ciências Administrativas da Universidade Federal de Pernambuco (DCA/UFPE). Pesquisadora do Observatório da Realidade Organizacional . E-mail: ddourado@ hotlink.com.br Artigo recebido em julho de 2004 e aceito em setembro de 2004.
} 
especificamente para discussões sobre a produção e a disseminação do conhecimento em administração; e os estudos a esse respeito são em quantidade e de uma qualidade crescentes, conforme indicam os números verificados nos anos de 2001, 2002 e 2003 (22, 28 e 37 respectivamente).

À medida que o campo da administração amadurece como uma área de conhecimento, verifica-se também a busca de sua consolidação no âmbito das ciências sociais. Martins (1996, p.3), ao abordar a epistemologia da pesquisa em administração, a considera uma ciência "em via de se fazer", razão pela qual julga imprescindível pesquisar a gênese de sua construção e organização.

O estudo das organizações e dos processos de administração tem sua base nas ciências sociais e se desenvolveu centrando seu foco na organização do trabalho, visando à produtividade. Essa origem remete a um contexto cuja marca fundamental é a Revolução Industrial que, no final do século XVIII, causou inegável impacto na organização do trabalho e da própria sociedade.

O positivismo é a marca original nas ciências sociais considerando que, ao elaborar uma disciplina - a sociologia - para estudar os fatos sociais, Augusto Comte delineou o que seria para ele o modo pelo qual essa disciplina atingiria status científico. Assim, os métodos das ciências naturais foram trazidos para os estudos sociológicos e determinaram a forma "correta" de se fazer ciência: submissão da imaginação à observação, capacidade de previsão, busca da certeza e da precisão, eliminando-se a indecisão, o vago (TRIVIÑOS, 1987). Essa concepção vem adequar-se à urgência de práticas eficazes para a gestão e o controle das atividades individuais envolvidas nos processos produtivos, contribuindo para a produção de conhecimentos eminentemente técnicos, funcionalmente orientados. Não é outra a orientação dos estudos pioneiros de Taylor, de Fayol e de seus seguidores.

A mutação da teoria da administração que deu origem à teoria das organizações, conforme caracteriza Motta (2001), ocorre a partir das idéias de Elton Mayo e, posteriormente, de Simon, sintetizadas na caracterização do "homo social", desmistificando a redução mecanicista proposta até então. Assim, o campo empírico da administração já não poderia se reduzir ao ambiente interno das organizações e tampouco poderia ignorar necessidades pessoais e do âmbito das relações humanas; tendo inicialmente considerado o homem apenas como mais uma peça da engrenagem das máquinas, ícones da Revolução Industrial. No campo teórico, a teoria das organizações é fruto da evolução da sociologia, da ciência política e da psicologia social norte-americanas, segundo o autor citado anteriormente, incorporando, em períodos mais recentes, abordagens da antropologia e da economia.

Essas abordagens contribuíram significativamente para ampliar o nível analítico e, conseqüentemente, o entendimento da complexidade de uma sociedade eminentemente organizacional, na qual as organizações representam o elo entre o indivíduo e o universo macrosocietário.

Por isso, analisar a produção de conhecimento em teoria das organizações é tarefa importante e complexa que vem sendo enfrentada por estudiosos brasileiros, sob vários aspectos, desde a orientação paradigmática dos estudos (MACHADO-DA-SILVA, CUNHA e AMBONI, 1990; CABRAL, 1998), passando por questões metodológicas (CAVEDON, 2001, CARRIERI e LUZ, 1998), incluindo análise de citações (CARVALHO JR. e VERGARA, 1996), até a avaliação da qualidade da produção científica brasileira nesse campo (BERTERO, CALDAS e WOOD JR., 1998; BERTERO e KEINERT, 1994), entre tantos outros.

A relevância da questão metodológica na construção do conhecimento, em qualquer área, é inerente à sua pretensão de cientificidade, uma vez que, segundo Demo (1996), a característica básica da produção do conhecimento científico é o questionamento sistemático. Diferentemente das verdades definitivas estabelecidas pelo senso comum, que quanto mais se afirmam mais valor adquirem, o conhecimento científico se valoriza por sua capacidade tanto de questionar as verdades estabelecidas como de ser permanentemente questionado. Tal desafio somente se concretiza mediante o ordenamento sistemático de procedimentos logicamente encadeados, aos quais o pesquisador recorre e torna explícitos. 
Machado-da-Silva, Cunha e Amboni (1990), num estudo sobre o estado da arte da produção acadêmica na área de organizações no Brasil, alertam para o fato preocupante de que dos 142 artigos examinados, 45,8\% deles adotavam abordagem exclusivamente teórica e $25,3 \%$ eram eminentemente empíricos. Para aqueles autores, somente a abordagem teórico-empírica reúne condições efetivas para a construção do conhecimento científico em organizações, que representavam, naquele estudo, 28,9\% do total analisado. Essa abordagem exige recursos metodológicos consistentes, capazes de alicerçar a base empírica, seja previamente orientada por uma teoria, seja para construí-la.

Considerando o caráter fundamental da questão metodológica para a qualidade do conhecimento produzido na área de teoria das organizações, este artigo apresenta uma revisão crítica da metodologia utilizada nos estudos publicados nos anais do Enanpad, no período de 1999 a 2002. O principal objetivo é contribuir com as discussões sobre práticas metodológicas, especialmente quanto ao uso do estudo de caso como estratégia de pesquisa. A versatilidade dessa estratégia tem contribuído para a grande disseminação de seu uso em estudos organizacionais. Contudo, observa-se que generalizar sua aplicação pode levar ao desvio de seus princípios originais e ao risco de torná-la meramente um rótulo metodológico. Por isso, julgou-se relevante resgatar a tipificação da estratégia de estudo qualitativo básico, proposta por Merriam (1998), sugerindo sua aplicabilidade nos estudos organizacionais.

O conjunto de pesquisas reunidas nos anais do Enanpad constitui referência significativa do que vem sendo produzido nos programas de pós-graduação no Brasil. $\mathrm{O}$ aumento da produção tem exigido sucessivos desmembramentos em novas áreas, como nas de "estratégia em organizações" (em 1997) e de "comportamento organizacional" (em 2001). Em razão dessa última ter estado incorporada à área objeto deste estudo nos anos de 1999 e 2000, foi necessário identificar e excluir os artigos publicados sob a abordagem comportamental, juntamente com os artigos cuja abordagem fosse exclusivamente teórica. Dessa forma, foram analisados 90 artigos considerados pertinentes à área de teoria das organizações, na qual são priorizados os níveis de análise organizacional, interorganizacional e societário.

Para nortear essa revisão crítica, apresenta-se, a seguir, a base teórica que sustenta as categorizações formuladas neste artigo.

\section{Paradigmas de pesquisa: pressupostos ontológicos, epistemológicos e metodológicos}

Um paradigma de pesquisa se constitui como um sistema de crenças básicas; isto é, uma visão de mundo que guia o investigador (GUBA e LINCOLN, 1994). Ao assumir essa definição de paradigma já se admite também que objetos de pesquisa, problemas pesquisados e métodos de coleta e análise serão, inevitavelmente, influenciados pela visão de mundo do pesquisador. Isso porque, segundo os mesmos autores, esse sistema de crenças se baseia em pressupostos ontológicos, epistemológicos e metodológicos por meio dos quais os investigadores explicitam suas concepções a respeito da natureza do mundo e do lugar ocupado pelos indivíduos, como também uma variedade de relacionamentos entre os fenômenos.

As questões ontológicas estão ligadas à forma e à natureza da realidade. Nesse sentido, o mundo seria real, podendo ser apreendido por meio do conhecimento de suas partes funcionais? Seria a realidade continuamente construída e reconstruída pela interação de indivíduos e grupos? Ou a realidade seria formatada e cristalizada, ao longo do tempo, pelo compartilhamento de valores sociais, políticos, culturais e econômicos?

As questões epistemológicas dizem respeito à natureza da relação entre sujeito e objeto pesquisado. Caso o fundamento ontológico esteja baseado na realidade dada como certa, concreta e passível de apreensão, a natureza epistemológica da pesquisa pressupõe a objetividade, a separação entre sujeito e objeto, e a verdade inquestionável dos resultados. No entanto, se a construção da realidade é mediada por valores, a natureza epistemológica da investigação é transacional e subjetiva e os resultados refletirão os valores do pesquisador.

As questões metodológicas se referem à forma pela qual o pesquisador buscará apreender a realidade. Se a realidade pode ser apreendida mediante o conhecimento de suas partes funcionais, é possível observá-la assepticamente e medi-la com precisão. No entanto, se a realidade é construída, só poderá ser apreendida 
mediante processos dialógicos/dialéticos, nos quais está clara a imersão e interação do pesquisador na própria realidade pesquisada (GUBA e LINCOLN, 1994).

Para esses autores, o positivismo se alinha com o entendimento da realidade como apreensível, na veracidade dos resultados obtidos e nos métodos experimentais. Na corrente pós-positivista, por sua vez, o absoluto cede lugar ao provável quanto à realidade e aos resultados, e com isso os experimentos precisam ser manipulados. Já a teoria crítica insere os valores sociais como fatores influenciadores da realidade e de seus achados, trazendo a dialética como metodologia ajustada aos seus pressupostos. Finalmente, o construtivismo parte da realidade como construída sob circunstâncias locais e específicas, os achados como criação dessa especificidade e os métodos adequados oriundos da fenomenologia. O quadro a seguir sintetiza os pressupostos básicos, orientadores das correntes de pesquisa, segundo essa abordagem.

\section{Quadro 1}

\section{Pressupostos básicos dos paradigmas de pesquisa}

\begin{tabular}{lllll}
\hline Ontologia & Positivismo & Pós-positivismo & Teoria crítica & Construtivismo \\
\hline apreensível. & $\begin{array}{l}\text { A realidade é } \\
\text { provavelmente } \\
\text { apreensível. }\end{array}$ & $\begin{array}{l}\text { A realidade é } \\
\text { moldada por valores } \\
\text { sociais, políticos, } \\
\text { econômicos etc., } \\
\text { cristalizados ao longo } \\
\text { do tempo. }\end{array}$ & $\begin{array}{l}\text { A realidade é } \\
\text { construída local e } \\
\text { especificamente. }\end{array}$ \\
\hline Epistemologia & $\begin{array}{l}\text { Os achados são } \\
\text { verdade. }\end{array}$ & $\begin{array}{l}\text { Os achados são } \\
\text { provavelmente } \\
\text { verdade. }\end{array}$ & $\begin{array}{l}\text { Os achados são } \\
\text { mediados por valores. }\end{array}$ & $\begin{array}{l}\text { Os achados são } \\
\text { criados. }\end{array}$ \\
\hline Metodologia & $\begin{array}{l}\text { Experimental/ } \\
\text { manipulativa. }\end{array}$ & $\begin{array}{l}\text { Experimental } \\
\text { modificada; a } \\
\text { falsificação de } \\
\text { hipóteses e os } \\
\text { métodos qualitativos } \\
\text { podem ser incluídos. }\end{array}$ & Dialética. & $\begin{array}{l}\text { Hermenêutica/ } \\
\text { dialética. }\end{array}$ \\
& & & & \\
& & & & \\
& & & & \\
& & & & \\
& & & & \\
\hline
\end{tabular}

Fonte: adaptado de Guba e Lincoln (1994).

Na visão de Morgan e Smircich (1980), dois extremos sustentam um continuum entre abordagens objetivistas e abordagens subjetivistas nas ciências sociais, estando subjacentes à diferenciação entre métodos quantitativos e qualitativos, não apenas no que diz respeito à coleta e análise de dados, mas quanto à própria concepção da pesquisa, desde o estágio de reflexão acerca do tema e da formulação do problema até os resultados e recomendações.

Tendo em vista a origem positivista das ciências sociais, tanto quanto da administração, as pesquisas guardavam forte relação, até meados da década de 1970, com os pressupostos ontológicos e epistemológicos vinculados a uma concepção do mundo formado por partes isoladas. A concentração exclusiva em fatos observáveis, desconsiderando os aspectos relacionais entre fenômenos, desvinculava a pesquisa do mundo social, supondo-se que a busca do conhecimento científico deveria se guiar por propósitos superiores de conhecer e não de intervir. Como intervenção era entendida não apenas a ação prática, mas também a aproximação ou a interação do pesquisador com seu objeto de estudo.

A evolução dos estudos sociológicos e a crescente complexidade social puseram em cheque a propriedade de métodos oriundos das ciências naturais, considerando-se especialmente as limitações de técnicas experimentais ou meramente enumerativas para a compreensão de fenômenos histórica e culturalmente situados, cujos imbricamentos passavam à margem da ênfase quantitativa. Embora o método qualitativo também tenha sua origem em fins do século XIX (CRESWELL, 1994), é a partir da década de 1970 que passa a ser mais fortemente discutido como recurso para estudos organizacionais empíricos. 
Morgan e Smircich (1980) destacam a publicação de um número especial de Administrative Science Quarterly, em dezembro de 1979, enfocando métodos qualitativos, como o marco das preocupações com a busca de alternativas efetivas para a pesquisa no campo da teoria das organizações. A esses métodos se associam diferentes pressupostos ontológicos e epistemológicos, mais próximos ao pólo subjetivista das abordagens em ciências sociais.

Creswell (1994) discute a questão metodológica sob a noção de paradigma quantitativo e paradigma qualitativo, cujos pressupostos estão abrigados nas dimensões ontológica, epistemológica, axiológica, retórica e metodológica, diferenciando sobremaneira as duas abordagens.

Os estudos sob a égide do paradigma quantitativo investigam problemas humanos ou sociais, baseando-se em teorias compostas de variáveis, medidas numericamente e analisadas mediante procedimentos estatísticos, para determinar se as predições teóricas são verdadeiras (CRESWELL, 1994). Assim, têm início no processo dedutivo, mas são realizados empiricamente por processos de indução enumerativa (BRANNEN, 1995), para descobrir o tipo e a quantidade de sujeitos que numa determinada população têm características particulares que podem ser vistas a partir de uma amostra.

Sob o paradigma qualitativo, os estudos buscam entender problemas humanos ou sociais tendo como suporte um quadro complexo e holístico, formado prioritariamente com palavras que relatam a visão detalhada de informantes. Esses estudos são conduzidos em ambientes ou condições naturais (CRESWELL, 1994). Não obstante, a realização empírica ocorre por indução analítica, uma vez que são os conceitos e as categorias que são problematizados e não sua incidência e freqüência (BRANNEN, 1995).

O quadro a seguir mostra, resumidamente, as implicações dos pressupostos ontológicos, epistemológicos e metodológicos em ambos os paradigmas.

\section{Quadro 2}

Pressupostos paradigmáticos da pesquisa quantitativa e qualitativa

\begin{tabular}{|c|c|c|c|}
\hline Pressupostos & Questões & Paradigma quantitativo & Paradigma qualitativo \\
\hline Ontológicos & $\begin{array}{l}\text { Qual é a natureza da } \\
\text { realidade? }\end{array}$ & $\begin{array}{l}\text { A realidade é objetiva e } \\
\text { singular. }\end{array}$ & $\begin{array}{l}\text { A realidade é subjetiva e } \\
\text { múltipla. }\end{array}$ \\
\hline Epistemológicos & $\begin{array}{l}\text { Qual é a relação do } \\
\text { pesquisador com o } \\
\text { objeto de estudo? }\end{array}$ & $\begin{array}{l}\text { Isolamento do pesquisador } \\
\text { em relação ao objeto de } \\
\text { estudo. }\end{array}$ & $\begin{array}{l}\text { Interação entre o pesquisador e } \\
\text { o objeto de estudo. }\end{array}$ \\
\hline Metodológicos & $\begin{array}{l}\text { Qual é o processo } \\
\text { de pesquisa? }\end{array}$ & $\begin{array}{l}\text { - } \quad \text { Processo dedutivo; } \\
\text { - } \quad \text { Causa e efeito; } \\
\text { - } \quad \text { Descontextualização; } \\
\text { - } \quad \text { Generalizações levam à } \\
\text { predição, à explanação e ao } \\
\text { entendimento; } \\
\text { - } \quad \text { Acurácia e consistência } \\
\text { mediante validade e } \\
\text { confiabilidade. }\end{array}$ & $\begin{array}{l}\text { - } \quad \text { Processo indutivo; } \\
\text { - } \quad \text { Inter-relação de fatores; } \\
\text { - } \quad \text { Contextualização; } \\
\text { - } \quad \text { Padrões e teorias } \\
\text { desenvolvidas para o } \\
\text { entendimento; } \\
\text { - } \quad \text { Acurácia e consistência } \\
\text { mediante verificação. }\end{array}$ \\
\hline
\end{tabular}

Fonte: adaptado de Creswell (1994).

Aos paradigmas quantitativo e qualitativo estão associadas estratégias de pesquisa, métodos para coleta e análise de dados que permitem abordar problemas, explicar, entender, prever ou prescrever ações, em consonância com os pressupostos do pesquisador. Creswell (1994) associa experimentos, quase-experimentos e surveys ao paradigma quantitativo e etnografia, grounded theory, estudo de caso e fenomenologia ao paradigma qualitativo. 
Essa associação é compartilhada por diversos autores, à exceção do estudo de caso que, com alguma frequiência, lança mão de procedimentos quantitativos. Para Bryman (1995), por exemplo, o estudo de caso é uma estratégia em que a combinação entre métodos quantitativos e qualitativos traz resultados positivos para $o$ entendimento do problema, permitindo o uso combinado de diferentes instrumentos de coleta e análise de dados. Bruyne, Herman e Schoutheete (1991) mostram que, embora de cunho freqüentemente qualitativo, o estudo de caso pode se basear em medidas diacrônicas de variáveis, construindo séries cronológicas que, em estudos sobre mudança, por exemplo, permitem analisar relações de causa e efeito entre variáveis intervenientes.

Esses autores reforçam o aspecto versátil do estudo de caso, acrescentando às múltiplas técnicas de coleta e análise de dados, a possibilidade de atender a estudos exploratórios, descritivos ou essencialmente práticos. Ressaltam ainda que, pelas características dos dados que reúne, o estudo de caso na pesquisa organizacional situa-se no pólo real, aberto e descontrolado, num continuum que demarca graus de construção, limitação e manipulação dos objetos e campos pesquisados.

A potencialidade da estratégia de estudo de caso nas pesquisas organizacionais é razão para se buscar maior solidez em sua aplicação, particularmente em pesquisas que almejam constituir a fronteira do conhecimento da área, como as realizadas na pós-graduação. A próxima seção busca apresentar elementos para discutir essa temática.

\section{Estudo de caso: imprecisões e alternativas}

A versatilidade do estudo de caso parece gerar confusões na caracterização de estratégias de natureza qualitativa. Merriam (1998) discute essa questão afirmando que estudo de caso é um termo usado, muitas vezes, para indicar um tipo de pesquisa que não é claramente um experimento, um levantamento ou uma história, mas que carece de uma definição própria capaz de diferenciá-lo das outras formas de pesquisa qualitativa. O termo é aplicado muitas vezes nos estudos organizacionais para descrever qualquer pesquisa baseada em um único caso, como uma empresa, um grupo ou departamento. Para Stake (2000), não se trata de uma opção metodológica, mas sim da escolha do objeto a ser estudado, pois qualquer que seja o método, o termo denota que é o caso que é escolhido para estudo.

Outrossim, uma série de outros estudos, embora se orientem pelo paradigma qualitativo, não têm sido suficientemente diferenciados para caracterizarem uma estratégia de pesquisa específica, sendo em geral definidos pelo que não são. Não devem ser considerados estudos de casos, uma vez que não aprofundam a análise numa unidade funcional ou sistema circunscrito; tampouco etnografia, por não estarem focados nos aspectos culturais; nem grounded theory, pois a sua análise não se estende a ponto de gerar uma teoria substantiva. Merriam (1998) procura identificar positivamente as características desse conjunto de estudos, para o qual adota o rótulo guarda-chuva de "estudo qualitativo básico" ou genérico.

O quadro 3 apresenta, de forma comparativa, o que parece constituir os principais traços dessas duas estratégias de pesquisa, no entendimento dos autores deste estudo.

Quadro 3

Características do estudo de caso x estudo qualitativo básico

\begin{tabular}{ll}
\hline \multicolumn{1}{c}{ Estudo de caso } & \multicolumn{1}{c}{ Estudo qualitativo básico } \\
\hline Peculiaridade e/ou complexidade do objeto & $\begin{array}{l}\text { O caso é um instrumento para verificação de } \\
\text { questões estabelecidas a priori }\end{array}$ \\
\hline Relato rico e holístico & Inclui descrição, interpretação e compreensão \\
\hline $\begin{array}{l}\text { Estudo aprofundado sobre uma unidade ou sistema } \\
\text { demarcado e sobre sua relação com o contexto }\end{array}$ & $\begin{array}{l}\text { Identificaçâo de padrões recorrentes (categorias, } \\
\text { fatores, variáveis e temas) }\end{array}$ \\
\hline Freqüente deficiência teórica sobre o tema & Arcabouço teórico preexistente \\
\hline Fonte: adaptado de Merriam (1998) e Stake (2000). &
\end{tabular}


Quanto ao objeto do estudo de caso, vários autores citam como características típicas, a sua complexidade e a sua intrincada relação com o contexto (YIN, 1993, 1994; STAKE, 2000; MERRIAM, 1998). O estudo de caso fornece explicações sobre um caso circunscrito e elementos do seu contexto, em especial, numa situação ampla e complexa demais para ser abordada tomando-se o conjunto de casos (LAVILLE e DIONNE, 1999). As relações interorganizacionais são um exemplo de objeto que se enquadra nessas características (YIN, 1993).

No que concerne aos resultados, o estudo de caso é adotado, segundo Merriam (1998), "para se obter um entendimento aprofundado da situação e do significado para aqueles envolvidos". O estudo de caso propicia um relato rico e holístico, envolvendo múltiplas variáveis de potencial importância para avançar o conhecimento do fenômeno (p.41).

Freqüentemente, uma pesquisa qualitativa é iniciada justamente por causa da deficiência teórica sobre o tema. O estudo de caso se diferencia dos outros tipos de pesquisa qualitativa por se constituir em descrição e análise intensivas do caso, proporcionando insights que podem ser tomados como hipóteses úteis para estruturar futuras pesquisas sobre o tema (MERRIAM, 1998).

$\mathrm{Na}$ singularidade do caso reside a força e a fraqueza dessa estratégia. Uma vez que os recursos estão concentrados em um caso, existe a possibilidade de aprofundamento e o pesquisador pode ser mais criativo, não se limitando ao protocolo de pesquisa. Parece recomendável que o investigador concentre-se num segmento para não ser superficial, escolhendo-o de tal maneira que possa chegar a uma visão representativa do conjunto (LAVILLE e DIONNE, 1999). Todavia, a restrição ao caso oferece um terreno pobre para a generalização: "as conclusões de tal investigação valem de início para o caso considerado, e nada assegura, a priori, que possam se aplicar a outros casos" (p.156). Diante desse argumento, do caso deve decorrer a validade interna; ou seja, a consistência entre a realidade observada e os resultados do caso (a força), obtida mediante um delineamento acurado dos métodos. Entretanto, a validade externa ou o grau de representatividade dos achados de pesquisa não pode ser defendida (a fraqueza), a menos que estes sirvam como insights para uma apreciação crítica de realidades de alguma forma semelhantes (BABBIE, 1999).

No estudo qualitativo básico, o pesquisador se acerca do caso escolhido com as questões críticas já em mente e procura verificar, através de descrição, interpretação e compreensão, como elas ali se manifestam. Isso contrasta com o que ocorre num estudo de caso clássico, cujo delineamento conduz o pesquisador a entender o que é importante no caso em si. A análise dos dados, no estudo qualitativo básico, comumente, resulta em uma identificação de padrões recorrentes, através do emparelhamento com conceitos, modelos e teorias.

Pelas imprecisões que rondam a definição e aplicação da estratégia de estudo de caso e pela relativa novidade da pesquisa qualitativa básica, como alternativa para caracterizar um tipo específico de estudo, este artigo destaca, na análise dos dados, as características de ambas.

\section{Metodologia}

Para proceder à revisão crítica da metodologia usada na produção mais recente da área de organizações/teoria das organizações foi realizado um levantamento dos artigos apresentados no Enanpad, de 1999 a 2002. Nesse período foram apresentados 194 artigos, incluindo textos da atual área organizações/comportamento organizacional, que até o ano 2000 encontrava-se integrada à de teoria das organizações. Levando em conta 0 foco deste estudo em artigos teórico-empíricos na área de teoria das organizações, foi analisado um total de 90 artigos, uma vez que foram excluídos os textos da área comportamental, bem como os ensaios teóricos ou revisões de literatura.

As informações coletadas foram subdivididas em três grupos, contemplando o delineamento da pesquisa, as técnicas de coleta de dados e as dimensões e recursos de análise de dados. Numa primeira etapa, foram coletados dados gerais de cada artigo, de forma meramente transcritiva, para identificá-lo e demarcar seus objetivos, questões de pesquisa ou hipóteses, técnicas de coleta e análise de dados. Outro conjunto de características foi levantado por meio de uma análise de conteúdo. Nesse caso se inclui a identificação da estratégia de pesquisa e dos pressupostos ontológicos e epistemológicos. A classificação das estratégias de 
pesquisa foi realizada com base no que foi possível depreender da metodologia, explicitada ou não pelos autores desses artigos. Sabe-se que muitos destes derivam de dissertações de mestrado ou teses de doutorado, concluídas ou em andamento. Nem sempre os autores dedicam espaço nos seus textos para a apresentação de aspectos metodológicos. Em alguns casos, é provável que falte a devida atenção às questões metodológicas, mesmo no texto original. Em outros, no entanto, é possível inferir que, na adaptação para a forma de artigo, a parte metodológica deixou de ser apresentada deliberadamente. Isso pôde ser constatado em alguns artigos em que na seção de referências bibliográficas era feita menção a fontes metodológicas que, entretanto, não constavam do texto. Essas limitações podem ser eventualmente debitadas à delimitação do número de páginas dos artigos. Tal prática foi, inclusive, objeto de atenção dos coordenadores de áreas do Enanpad em 2003, com o aumento de uma página no tamanho dos artigos e a recomendação de que esse espaço fosse destinado a um maior detalhamento da metodologia.

Maior dificuldade foi encontrada na identificação dos pressupostos ontológicos e epistemológicos dos artigos, em razão dos problemas apontados por Triviños (1987); quais sejam, a liberalidade no uso de conceitos, o ecletismo e a relativa incoerência entre teoria e método. Esses problemas se tornam mais graves em artigos por causa do limitado número de páginas, conforme já apontado.

Martins (1996), ao realizar um levantamento sobre abordagens metodológicas em pesquisas na área de administração, constatou que os estudos teóricos que têm como fonte outras publicações apresentam uma argumentação mais sólida sobre o tema desenvolvido. Já os autores de pesquisas empírico-analíticas, "minimizam a discussão, o confronto, o debate ou o questionamento" (p.11). Vale ressaltar que o estudo de Martins (1996) concentrou-se em dissertações de mestrado e teses de doutorado defendidas em programas de pós-graduação, que por sua natureza apresentam maior aprofundamento teórico e metodológico do que os artigos apresentados no Enanpad.

Nesta pesquisa os comentários em relação aos pressupostos ontológicos e epistemológicos são, portanto, indicativos de postura tendente ao subjetivismo ou ao objetivismo, sendo esta mais uma limitação deste estudo.

\section{Apresentação e análise dos dados}

Esta análise segue um ordenamento lógico que, partindo do tipo de pesquisa (quantitativo, qualitativo ou multimétodo) encadeia-se com as estratégias, as técnicas de coleta e análise de dados verificados nos textos apresentados na área de organizações/teoria das organizações, no período de 1999 a 2002. Tendo em vista a declarada prioridade da área em contemplar os níveis organizacional, interorganizacional e societário de análise, julgou-se importante verificar também o grau de pertinência dos estudos apresentados segundo esse critério. Ao final da seção, tenta-se inferir as tendências ontológicas e epistemológicas que orientaram os pesquisadores em seus estudos. O recurso à inferência deve-se ao fato de que, na maioria das vezes, os autores não deixam explícitas suas orientações. A indicação tendencial, portanto, tem conotação especulativa e é uma tentativa de situar as abordagens quanto aos aspectos de subjetividade ou objetividade.

É na integração e interpretação dos dados apresentados e à luz dos construtos referentes à produção do conhecimento, especialmente relacionados a questões metodológicas, que este estudo se posiciona criticamente a respeito da produção científica da área, guardadas suas devidas limitações.

\section{Tipos de pesquisa}

Quando analisados os resultados referentes ao tipo de pesquisa, percebe-se, de acordo com a tabela 1, a grande predominância da pesquisa qualitativa nos artigos analisados, sendo apenas 13,33\% dos textos caracterizados como puramente quantitativos. Por si só, esses dados não oferecem grande potencial de análise. No entanto, a comparação deles com outras categorias em análise oferecem insights interessantes para a crítica ao posicionamento metodológico dos pesquisadores da área. 
Tabela 1

Distribuição de freqüência dos artigos por tipos de pesquisa

\begin{tabular}{lcc}
\hline \multicolumn{1}{c}{ Tipo de pesquisa } & Freqüência & Percentual \\
\hline Qualitativa & 70 & $77,78 \%$ \\
Quantitativa & 12 & $13,33 \%$ \\
Multimétodo & 8 & $8,89 \%$ \\
Total & 90 & $100,00 \%$ \\
\hline
\end{tabular}

\section{Estratégias de pesquisa}

A tabela 2 apresenta a distribuição das estratégias de pesquisa adotadas nos artigos. A maioria das pesquisas adotou exclusivamente a estratégia de estudo de caso (31\%) ou de estudo qualitativo básico (30\%), sendo que a soma das duas representa $78 \%$ das pesquisas exclusivamente qualitativas. Por essa razão, a análise se concentrará nessas duas estratégias.

Foi observado que o estudo de caso é uma abordagem bastante difundida na área. Já o conceito de estudo qualitativo básico não foi adotado na autoclassificação das estratégias de pesquisa de nenhum dos artigos. Para o estudo de caso, foram encontradas três situações: na primeira, os autores assim o denominavam de modo acertado, conforme a categorização proposta neste estudo. Numa segunda situação, não houve indicação da metodologia adotada, porém, por suas características, o artigo foi considerado um estudo de caso. Por último, apesar de considerados um estudo de caso, foi constatado que não apresentavam características suficientes para serem enquadrados como tal, de acordo com o quadro 3. Em grande parte dessas situações, julgou-se que seria mais apropriado classificá-los como estudo qualitativo básico, conforme os critérios ali apresentados. Dessa forma, a distribuição dos artigos sob a denominação de estudo qualitativo básico foi determinada mediante a categorização aqui sugerida, uma vez que não haviam sido assim identificados originalmente por seus respectivos autores.

Tabela 2

Distribuição de freqüência dos artigos por estratégias de pesquisa

\begin{tabular}{lcc}
\hline \multicolumn{1}{c}{ Estratégia de pesquisa } & Freqüência & Percentual \\
\hline Estudo de caso & 28 & $31,11 \%$ \\
\hline Estudo qualitativo básico & 27 & $30,00 \%$ \\
\hline Survey & 12 & $13,33 \%$ \\
\hline Etnografia & 5 & $5,56 \%$ \\
\hline Pesquisa-ação & 4 & $4,44 \%$ \\
\hline Estudo de caso com outras estratégias & 3 & $3,33 \%$ \\
\hline Estudo qualitativo básico com outras estratégias & 3 & $3,33 \%$ \\
\hline Estudos biográficos & 1 & $1,11 \%$ \\
\hline Fenomenologia & 1 & $1,11 \%$ \\
\hline Estudo experimental & 1 & $1,11 \%$ \\
\hline Não identificado & 5 & $5,56 \%$ \\
\hline Total & 90 & $100,00 \%$ \\
\hline
\end{tabular}

Especialmente na definição entre estudo de caso e estudo qualitativo básico, as diferenças são, em alguns casos, bastante sutis. A classificação adotada aqui é ilustrada com alguns exemplos. O primeiro é de um artigo, cuja designação original de estudo de caso pareceu pertinente, pois, na parte analítica, os autores demonstraram conhecimento aprofundado sobre os meandros do poder na empresa em foco, descrito com riqueza de detalhes. Em outro texto, que investigou as relações interorganizacionais associadas a um projeto agroindustrial, sobressaíram a complexidade do objeto investigado e a sua intrincada relação com o contexto, aspectos suficientemente apresentados no artigo, que justificam seu enquadramento como estudo de caso. 
Outra pesquisa analisou a evolução da estrutura organizacional de uma empresa ao longo dos anos. Apesar da qualidade da análise, o referencial teórico utilizado, bastante difundido no Brasil, não apresentava maiores desafios na sua aplicação, parecendo que o estudo, principalmente por essa razão, pode ser considerado um estudo qualitativo básico. Outros estudos em que os pesquisadores se acercavam de um caso, sem uma particular singularidade ou complexidade - munidos de um referencial teórico claramente operacionalizado, que possibilitava corroborar ou refutar determinados aspectos da teoria - foram então classificados como estudos qualitativos básicos.

\section{Técnicas de coleta de dados}

No que se refere às técnicas de coleta de dados, constata-se, conforme mostra a tabela 3, que em 73,3\% dos artigos foi utilizada a técnica de entrevista, isoladamente ou em combinação com outras técnicas, apontando para uma clara preferência dos pesquisadores. Os questionários surgem como a segunda opção de técnica de coleta. Por outro lado, as fontes secundárias, quando usadas em combinação, incidem como a segunda fonte de dados escolhida. A diversidade de fontes e a combinação de técnicas sugerem que a triangulação de dados é uma preocupação freqüente dos pesquisadores.

Tabela 3

Distribuição de freqüência dos artigos por técnicas de coleta de dados

\begin{tabular}{lcc}
\hline Técnica de coleta de dados & Freqüência & Percentual \\
\hline Entrevista e fontes secundárias & 30 & $33,30 \%$ \\
\hline Entrevista e outras & 20 & $22,20 \%$ \\
\hline Entrevista & 16 & $17,80 \%$ \\
\hline Questionário & 7 & $7,80 \%$ \\
\hline Multitécnicas & 7 & $7,80 \%$ \\
\hline Questionário e outras & 4 & $4,40 \%$ \\
\hline Fontes secundárias & 2 & $2,20 \%$ \\
\hline Observação e fontes secundárias & 1 & $1,11 \%$ \\
\hline Não identificada & 3 & $3,30 \%$ \\
\hline Total & 90 & $100,00 \%$ \\
\hline
\end{tabular}

Não foram constatadas diferenças significativas quanto à quantidade de técnicas de coleta de dados utilizadas nos estudos de caso e nos estudos qualitativos básicos, conforme se depreende da tabela 4. Isso pode sugerir que a maior profundidade relativa atingida nos estudos de caso não depende da variedade de técnicas de coleta empregadas. Alternativas de explicação podem ser a forma como essas técnicas foram utilizadas, a análise subseqüente dos dados, bem como o principal instrumento de coleta (o próprio pesquisador) ou, ainda, o maior tempo de imersão no campo de pesquisa.

Tabela 4

Distribuição de freqüência de artigos por número de técnicas de coleta de dados nos estudos de caso e nos estudos qualitativos básicos

\begin{tabular}{lcc}
\hline \multicolumn{1}{c}{ Técnicas de coleta } & Estudo de caso & Estudo qualitativo \\
\hline Uso de uma técnica & 7 & 7 \\
\hline Uso de duas técnicas & 11 & 13 \\
\hline Uso de três técnicas & 6 & 6 \\
\hline Uso de quatro técnicas* & 3 & 1 \\
\hline Total & $27 * *$ & 27 \\
\hline
\end{tabular}

* Trata-se da combinação de entrevista, questionário, dados secundários e observação.

** Em um dos estudos de caso não foi possível identificar a técnica de coleta de dados. 


\section{Técnicas de análise de dados}

Quanto às técnicas de análise de dados utilizadas nos artigos, mostradas na tabela 5 , é verificada uma forte concentração (quase 50\%) na abordagem interpretativa. Se esta for considerada como pelo menos uma das técnicas utilizadas, sua participação se aproxima de $60 \%$ do total dos artigos. Desse resultado, é possível inferir que a presença dos métodos interpretativos ocorre por sua adequação à pesquisa qualitativa, também observada como abordagem predominante (com quase $80 \%$ dos casos).

Assim, as técnicas de análise interpretativas, compreendendo análise de conteúdo, documental, simbólica, de discurso e outras se configuram como meios ajustados para inferir conclusões de entrevistas, narrativas, documentos, discursos e observações.

Por outro lado, também os procedimentos estatísticos foram utilizados como técnica de análise $(32,23 \%)$. Nesse sentido, é preciso considerar que o uso desses recursos não ficou restrito aos métodos quantitativos. Também algumas abordagens qualitativas, tendo o estudo de caso como estratégia principal, valeram-se desse tipo de procedimento em seus levantamentos e na associação com técnicas interpretativas, reforçando a adequação dessa estratégia em abordagens multimétodo.

Tabela 5

Distribuição de freqüência dos artigos por técnicas de análise de dados

\begin{tabular}{lcc}
\hline \multicolumn{1}{c}{ Técnica de análise de dados } & Freqüência & Percentual \\
\hline Métodos interpretativos & 44 & $48,88 \%$ \\
\hline Métodos estatísticos & 29 & $32,23 \%$ \\
\hline Métodos estatísticos e interpretativos & 7 & $7,78 \%$ \\
\hline Não identificados & 10 & $11,11 \%$ \\
\hline Total & 90 & $100,00 \%$ \\
\hline
\end{tabular}

\section{Nível de análise}

No que se refere ao nível de análise, constata-se forte predominância no estrato organizacional (60\%). Se forem aduzidos os níveis interorganizacionais e societários recomendados pela área temática do fórum, perfaz-se uma fatia de quase $2 / 3$ do total dos artigos. Apenas uma minoria, menos de $20 \%$, está voltada para os níveis individual e grupal. Esse resultado, apresentado na tabela 6, pode decorrer do fato de ainda ser recente a criação da área específica para estudos comportamentais. Pode igualmente resultar da dificuldade encontrada neste levantamento de se distinguir essas temáticas que, em alguns casos, podem estar superpostas.

Tabela 6

Distribuição da freqüência dos artigos por técnicas de análise de dados

\begin{tabular}{lcc}
\hline Nível de análise & Freqüência & Percentual \\
\hline Organizacional & 54 & $60,00 \%$ \\
\hline Interorganizacional & 10 & $11,11 \%$ \\
\hline Individual & 9 & $10,00 \%$ \\
\hline Multinível & 8 & $8,89 \%$ \\
\hline Grupal & 7 & $7,78 \%$ \\
\hline Societário & 2 & $2,22 \%$ \\
\hline Total & 90 & $100,00 \%$ \\
\hline
\end{tabular}




\section{Objetividade e subjetividade nos pressupostos ontológicos e epistemológicos}

Por razões já citadas ao longo deste artigo, a identificação dos pressupostos ontológicos e epistemológicos dos artigos analisados foi tarefa das mais complexas. No entanto, essa tentativa foi feita mediante a confluência dos objetivos, das perguntas ou hipóteses e do arcabouço teórico e metodológico adotado nas investigações. Com base no continuum proposto por Morgan e Smircich (1980), o quadro 4 apresenta as tendências observadas, no tocante à objetividade ou subjetividade na orientação dos artigos analisados.

\section{Quadro 4}

\section{Tendências ontológicas e epistemológicas dos artigos analisados}

\begin{tabular}{|c|c|c|c|c|c|}
\hline $\begin{array}{l}\text { Realidade como } \\
\text { uma projeção da } \\
\text { imaginação } \\
\text { humana }\end{array}$ & $\begin{array}{l}\text { Realidade } \\
\text { como uma } \\
\text { construção } \\
\text { social }\end{array}$ & $\begin{array}{l}\text { Realidade } \\
\text { como um } \\
\text { campo de } \\
\text { discurso } \\
\text { simbólico }\end{array}$ & $\begin{array}{l}\text { Realidade } \\
\text { como um } \\
\text { campo } \\
\text { contextual de } \\
\text { informação }\end{array}$ & $\begin{array}{l}\text { Realidade } \\
\text { como um } \\
\text { processo } \\
\text { concreto }\end{array}$ & $\begin{array}{l}\text { Realidade } \\
\text { como uma } \\
\text { situação } \\
\text { concreta }\end{array}$ \\
\hline $\begin{array}{l}\text { Para obter } \\
\text { insight } \\
\text { fenomenológico, } \\
\text { revelação }\end{array}$ & $\begin{array}{l}\text { Para entender } \\
\text { como a } \\
\text { realidade } \\
\text { social é criada }\end{array}$ & $\begin{array}{l}\text { Para entender } \\
\text { padrões do } \\
\text { discurso } \\
\text { simbólico }\end{array}$ & $\begin{array}{l}\text { Para mapear o } \\
\text { contexto }\end{array}$ & $\begin{array}{l}\text { Para estudar } \\
\text { os sistemas, } \\
\text { os processos, } \\
\text { a mudança }\end{array}$ & $\begin{array}{l}\text { Para construir } \\
\text { uma ciência } \\
\text { positivista }\end{array}$ \\
\hline \multicolumn{3}{|c|}{ Abordagem subjetivista } & \multicolumn{3}{|c|}{ Abordagem objetivista } \\
\hline \multicolumn{3}{|c|}{$47,55 \%$} & \multicolumn{3}{|c|}{$52,45 \%$} \\
\hline
\end{tabular}

Fonte: adaptado de Morgan e Smircich (1980).

Para ilustrar a categorização feita, pode-se citar um estudo cujo objetivo foi medir o grau de sustentabilidade organizacional e testar um instrumento para tal medida. A conclusão foi a de que a abordagem dessa pesquisa situou-se no pólo extremo da objetividade, uma vez que analisou uma situação concreta; qual seja, o gerenciamento dos resíduos sólidos adotado por empresas de franquia no setor de alimentação. A estratégia utilizada foi survey, usando-se escalas de medição e tratamento quantitativo de dados, apresentados basicamente em forma de estatística descritiva. A mesma estratégia foi empregada para estudar a adaptabilidade das empresas e o papel que a qualidade e a sua certificação podem ter no processo de mudança estrutural, num ambiente de extremo dinamismo, valorizando o sistema funcional.

Outro estudo visou identificar os aspectos que estão relacionados com a viabilidade de associações de produtores rurais. Para tal, foi realizado um estudo comparativo de casos - selecionados por suas características exemplares -, coletando dados mediante entrevistas semi-estruturadas, em profundidade, valorizando as experiências internas e particulares dos sujeitos. Os dados foram analisados de forma interpretativa, procurando captar a percepção dos associados, dirigentes e agentes externos, denotando, para esses autores, uma pressuposição na construção social da realidade. Sob essa pressuposição também foi analisado o processo de institucionalização em um museu de arte moderna, baseando-se na teoria institucional e na perspectiva do poder, com coleta de dados através de entrevistas e de documentação secundária, discursivamente analisados.

Visto que a pesquisa qualitativa predominou na grande maioria dos artigos analisados (78\%), era de se esperar que a abordagem subjetivista predominasse. Contudo, a análise dos artigos mostrou que a maioria $(52,45 \%)$ adotou uma abordagem objetivista, demonstrando uma clara influência positivista na administração, bem como a força de seus pressupostos para os estudos organizacionais. 


\section{Comentários e considerações finais}

Em relação ao foco deste artigo, a análise crítica das metodologias empregadas nos artigos do Enanpad na área de organizações/teoria das organizações, os resultados possibilitam as seguintes considerações:

- a área de organizações/teoria das organizações caracterizou-se por uma predominância de estudos qualitativos, nos anos considerados. Vale salientar que essa predominância não vem acompanhada de uma fidelidade aos pressupostos e conceitos que norteiam o paradigma qualitativo, conforme propõem autores como Creswell (1994) e Morgan e Smircich (1980);

- das nove estratégias de pesquisa empregadas na classificação das metodologias, o estudo de caso e o estudo qualitativo básico dividiram uma posição de destaque em relação às demais estratégias. Contudo, foi revelada uma vulgarização na utilização do termo "estudo de caso", denotando uma falta de aprofundamento no conhecimento dessa estratégia;

- foi constatada maior tendência dos autores à adoção de pressupostos objetivistas, revelando a força da resistência do paradigma positivista na área de teoria organizacional, apesar da predominância dos estudos qualitativos;

- embora os resultados mostrem incidência um pouco maior de pressupostos ontológicos e epistemológicos com tendência ao objetivismo, os métodos predominantes de análise dos dados foram interpretativos. Conclui-se, portanto, que numa parte das pesquisas com pressupostos objetivistas, foram adotadas técnicas de análise interpretativas, de natureza mais subjetiva. Isso aponta para duas alternativas: a interpretação está sendo utilizada para enriquecimento da análise - que, do contrário, seria puramente quantitativa - ou revela uma inconsistência paradigmática;

- a pesquisa qualitativa, sobretudo o estudo de caso e o estudo qualitativo básico, configurara-se como o meio de investigação por excelência empregado na área de teoria das organizações. Ao contrário do que alguns autores sugerem - como por exemplo, Cooper e Schindler (2003) -, o estudo de caso atende aos critérios de um estudo formal, e não aos de uma fase meramente exploratória da pesquisa;

- uma contribuição desse estudo está associada ao problema do enquadramento das pesquisas como estudo de caso. Foi constatado que o estudo de caso e o estudo qualitativo básico perfizeram cerca de $2 / 3$ das pesquisas apresentadas no período. Este levantamento sugere que a categoria de estudo "qualitativo básico", proposta por Merriam (1998), pode ser proveitosa para os pesquisadores brasileiros na área de administração. Isso pode melhor demarcar as propriedades de determinadas estratégias de pesquisa qualitativa que são, indevidamente, confundidas com outras, em especial com o estudo de caso clássico. A relevância desse ponto não se prende à mera rotulação de estratégias, mas ao melhor entendimento, pelos próprios pesquisadores, do papel fundamental que alguns elementos de uma estratégia exercem numa investigação, como é o caso da relação entre os dados e a teoria.

Finalizando, percebe-se que a natureza aplicada e a orientação pragmática da administração não dispensam uma base filosófica coerente que dê suporte às várias partes de uma investigação (TRIVIÑOS,1987). Nesse sentido, a falta de uma disciplina intelectual impossibilita identificar a verdadeira natureza do problema a ser investigado, podendo resultar na confusão entre "problemas essenciais" e "questões secundárias" (p.16). O autor atribui à falta de uma "amarra de conceitos centrais orientadores" (p.13), o fato de tantas dissertações de mestrado ou teses de doutorado permanecerem intocadas nas prateleiras das nossas bibliotecas. A mescla de posturas intelectuais e as citações avulsas não denotam uma superior qualidade das pesquisas, mas, ao contrário, revelam fraqueza intelectual, que procura se esconder por trás de um "ecletismo obscuro" (p.16). Além da consistência teórica interna, Triviños (1987) salienta a necessidade da coerência entre a teoria e a prática social do pesquisador. 


\section{Referências bibliográficas}

BABBIE, E. Métodos de pesquisas de survey. Belo Horizonte: UFM G, 1999.

BERTERO C. O.; CALDAS, M. P.; WOOD Jr., T. Produção científica em administração de empresas: provocações, insinuações e contribuições para um debate local. In: ENCONTRO ANUAL DA ASSOCIAÇÃO NACIONAL DOS PROGRAM AS DE PÓS-GRADUAÇÃO EM ADM INISTRAÇÃO, 22., 1998, Foz do Iguaçu. Anais... Foz do Iguaçu: Anpad, 1998. 1 CD-ROM. $\overline{1} \overline{9} \overline{4}$.

; KEINERT, T. M. M. A evolução da análise organizacional no Brasil. Revista de Administração de Empresas, v.34, n.3, p.81-90,

BRANNEN, J. Combining qualitative and quantitative approaches: an overview. In: BRANNEN, J. (Ed.). Mixing methods: qualitative and quantitative research. Aldershot: Avebury, 1995. p.3-37.

BRUYNE, P.; HERMAN, J.; SCHOUTHEETE, M. Os modos de investigação. In: BRUYNE, P.; HERMAN, J.; SCHOUTHEETE, M. Dinâmica da pesquisa em ciências sociais: os pólos da prática metodológica. 5.ed. Rio de Janeiro: Francisco Alves, 1991. p.221-251.

BRYMAN, A. The debate about quantitative and qualitative research. In: BRYMAN, A. Quantity and quality in social research. London : Routledge, 1995. p. 93-126.

CABRAL, A. C. A. Reflexões sobre a pesquisa nos estudos organizacionais: em busca da superação da supremacia dos enfoques positivistas. In: ENCONTRO ANUAL DA ASSOCIAÇÃO NACIONAL DOS PROGRAMAS DE PÓS-GRADUAÇÃO EM ADMINISTRAÇÃO, 22., 1998, FOZ do Iguaçu. Anais... Foz do Iguaçu: Anpad, 1998. 1 CD-ROM.

CARRIERI, A. P.; LUZ, T. R. Paradigmas e metodologias: não existe pecado do lado de baixo do Equador. In: ENCONTRO ANUAL DA ASSOCIAÇÃO NACIONAL DOS PROGRAM AS DE PÓS-GRADUAÇÃO EM ADM INISTRAÇÃO, 22., 1998, Foz do Iguaçu. Anais... Foz do Iguaçu: Anpad, 1998. 1 CD-ROM.

CARVALHO JR., D.; VERGARA, S. C. Refletindo sobre as possíveis conseqüências da análise organizacional apoiada em referências estrangeiras. Revista de Administração Pública, Rio de Janeiro, v.30, n.6, p.123-138, 1996.

CAVEDON, N. R. Recursos metodológicos e formas alternativas no desenvolvimento e na apresentação de pesquisas em administração. In: ENCONTRO ANUAL DA ASSOCIAÇÃO NACIONAL DOS PROGRAMAS DE PÓS-GRADUAÇÃO EM ADMINISTRAÇÃO, 25., 2001, Campinas. Anais... Campinas: Anpad, 2001. 1 CD-ROM.

COOPER, D. R.; SCHINDLER, P. S. Métodos de pesquisa em administração. 7.ed. Porto Alegre: Bookman, 2003.

CRESWELL, J. W. Research design: qualitative \& quantitative approaches. Thousand Oaks: Sage, 1994.

DEMO, P. Pesquisa e construção do conhecimento: metodologia científica no caminho de Habermas. 2.edição. Rio de Janeiro: Tempo Brasileiro, 1996.

GUBA, E. G.; LINCOLN, Y. S. Competing paradigm in qualitative research. In: DENZIN, N. K; LINCOLN, Y. S. (Eds.). Handbook of qualitative research. London: Sage, 1994. p. 105-117.

LAVILLE, C., DIONNE, J. A construção do saber. Porto Alegre: UFM G/Artmed, 1999.

MACHADO-DA-SILVA, C.; CUNHA, V. C.; AMBONI, N. Organizações: o estado da arte da produção acadêmica no Brasil. In: ENCONTRO ANUAL DA ASSOCIAÇÃO NACIONAL DE PROGRAMAS DE PÓS-GRADUAÇÃO EM ADMINISTRAÇÃOO, 14., 1990, Florianópolis. Anais... Belo Horizonte: Anpad, 1990. v.6, p.11-28. (Organizações).

MARTINS, G. A. Epistemologia da pesquisa em administração. In: ENCONTRO ANUAL DA ASSOCIAÇÃO NACIONAL DOS PROGRAMAS DE PÓS-GRADUAÇÃO EM ADMINISTRAÇÃO, 20., 1996, Angra dos Reis. Anais... [S.I.]: Anpad, 1996. p.2-14. (Formação e treinamento de administradores).

MERRIAM, S. B. Qualitative research and case study applications in education. San Francisco: Jossey- Bass, 1998.

MORGAN, G.; SM IRCICH, L. The case for qualitative research. Academy of Management Review, v.5, n.4, p.491-500, 1980.

MOTTA, F. C. P. Teoria das organizações: evolução e crítica. 2.ed. São Paulo: Pioneira Thomson Learning, 2001.

STAKE, R. Case studies. In: DENZIN, N. K.; LINCOLN, Y. S. Handbook of qualitative research. 2.ed. Thousand Oaks: Sage, 2000. p.435-454.

TRIVIÑOS, A. N. S. Introdução à pesquisa em ciências sociais: a pesquisa qualitativa em educação. São Paulo: Atlas, 1987.

YIN, R. K. Applications of case study research. Thousand Oaks: Sage, 1993.

Case study research: designs and methods. 2.ed. Thousand Oaks: Sage, 1994. 